\title{
Albuminuria and its associated biomedical factors among indigenous adults in Far North Queensland: a 7-year follow up study

Ming $\mathrm{Li}^{i^{*}}$ and Robyn McDermott ${ }^{2}$

\begin{abstract}
Background: To document albuminuria prevalence and its associated factors in Aboriginal and Torres Strait Islander (TSI) adults with high renal and metabolic risks from 19 rural and remote north Queensland communities.

Methods: One thousand nine hundred seventy-one indigenous adults were enrolled in 1998 and 566 completed follow up in 2007 in this population-based study. Measurements included weight, waist circumference (WC), blood pressure (BP), fasting glucose, lipids, gamma-glutamyltransferase (GGT), urinary albumin creatinine ratio (UACR), smoking, alcohol intake and physical activity (PA). Albuminuria was defined as an UACR $>=2.5 \mathrm{~g} / \mathrm{mol}$ in males and $>=3.5 \mathrm{~g} / \mathrm{mol}$ in females. The association between albuminuria and biomedical factors was assessed with generalised linear modelling.

Results: Baseline albuminuria prevalence was $19.7 \%$ (95 \% Cl: 18.0-21.6 \%). Follow up prevalence was $42.4 \%$ (95\% Cl: 38.4-46.5\%) among the 566 adults having the $2^{\text {nd }}$ UACR measurements. Follow-up albuminuria was associated with fasting glucose of $5.4 \mathrm{mmol} / \mathrm{L}(\mathrm{OR} 2.5,95 \% \mathrm{Cl} 1.5-4.2)$, GGT tertiles in a dose-response manner (OR 2.0 for $2^{\text {nd }}$ and 3.7 for $3^{\text {rd }}$ tertile, $\mathrm{p}$ for trend $\left.<0.001\right)$, and abdominal overweight and obesity $(\mathrm{OR} 2.1,95 \% \mathrm{Cl}$ 1.1-3.9 and 5.4, $95 \% \mathrm{Cl}$ : 2.2-13.5 respectively). Aboriginal people with diabetes were three times more likely of having albuminuria compared to TSI counterparts, while TSI smokers had twice the likelihood (95 \% Cl 1.2-3.2). At both baseline and follow up, albuminuria was more prevalent among older participants.
\end{abstract}

Conclusions: Indigenous Australians in north Queensland are at high risk of albuminuria. Overweight and obesity, glycaemia, increased GGT, and smoking were associated with albuminuria at baseline and/or follow up.

Keywords: Albuminuria prevalence, Australian Indigenous populations, Overweight and obesity, Blood glucose and diabetes, Gamma-glutamyltransferase, Smoking

\section{Background}

Albuminuria is a pathological condition with excessive leakage of protein into the urine. It is an indicator of kidney damage and is an early manifestation of impaired kidney function leading to chronic kidney disease (CKD). CKD is becoming a worldwide public health problem [1] where individuals with kidney failure require dialysis or transplantation that poses a substantial pressure on the health-care system [2]. With an aging population and increasing prevalence of diabetes and

\footnotetext{
* Correspondence: ming.li@unisa.edu.au

'Centre for Population Health Research, Sansom Institute for Health Research, University of South Australia, IPC CWE-48, GPO Box 2471, Adelaide, SA 5001, Australia

Full list of author information is available at the end of the article
}

other chronic diseases, early detection and appropriate management of CKD becomes important [3]. From a public health perspective, screening for albuminuria to prevent CKD and cardiovascular disease (CVD) is feasible and cost effective in high risk populations [4-7], based on the consistent results among large population studies that albuminuria and proteinuria strongly and independently predict the risk of CKD progress, CVD, and all cause-mortality [8-10].

The Australian Diabetes, Obesity and lifestyle Study (AusDiab) reported a prevalence of micro albuminuria and macro albuminuria, defined as UACR $>=2.5 \mathrm{~g} / \mathrm{mol}$ for males and $>=3.5 \mathrm{~g} / \mathrm{mol}$ for females in a spot urine test, among over 25 year old Australians in 2000 as $6.0 \%$ and 
$0.6 \%$ respectively [11]. A five-year follow up of the same population showed a $0.8 \%$ annual incidence of albuminuria [12]. Aboriginal and TSI people are at substantially greater risk of having poorer health outcomes including CKD and associated hospitalization and deaths compared to nonIndigenous Australians [13]. Among screened volunteers from an isolated Northern Territory (NT) Aboriginal community during 1992-1995, 26 \% of adults had micro albuminuria and $24 \%$ had overt albuminuria [14], similar to the rate from screening surveys conducted in Aboriginal communities in South Australia (SA), Western Australia (WA) and Queensland (QLD) during 1995-1997 [15, 16]. We have shown that albuminuria predicts incidence of diabetes, hypertension, and coronary heart diseases among Indigenous adults in Far North Queensland [17-20]. Therefore, understanding albuminuria and its predictors is important in preventing and managing effectively these morbidities. However, the associated factors of albuminuria among Indigenous Australians are not well reported, and to date CKD has largely been focused on the evaluation of end-stage kidney disease (ESKD) using clinical data [13].

Here we aim to document the prevalence of albuminuria and its associated factors in two Indigenous populations from north Queensland.

\section{Methods}

\section{Study population}

This study included a subgroup of 1971 Indigenous participants aged over 18 years in far north Queensland in the "Well Person's Health Check" (WPHC). WPHC was a population based wellness screening program in 19 rural and remote Indigenous communities across three health districts during 1998-2000. Methods for this cross sectional study have been reported in detail elsewhere [21]. Briefly, all Indigenous residents of the communities aged 13 years and over were invited to attend a health check via local health services, community councils, and community groups. Based on the local census data, the study achieved a participation rate of $44.5 \%$ with greater participation noted in smaller communities. The follow-up data were collected during 2004-2007. Participants overall were not different demographically from the age and sex distribution of the Australian Indigenous population as a whole. Written informed consent was obtained from participants. The study protocols were approved by the Cairns Base Hospital Human Research Ethics Committee with support from the peak Indigenous Health Organizations, Apunipima Cape York Health Council and the Torres Strait and Northern Peninsula Area Health Council.

\section{Measurements}

Urine specimens provided by participants in sterile $50 \mathrm{~mL}$ containers were from the first morning void or a sample at least two hours from the most recent void. Dipstick urinalysis (Combur-test, Roche) tested the samples for protein, $\mathrm{pH}$, nitrites, leucocytes and blood. UACR was measured by immunoassay in $\mathrm{g} / \mathrm{mol}$ in Cairns Base Hospital. Albuminuria was defined as having $\mathrm{UACR}>=2.5 \mathrm{~g} / \mathrm{mol}$ in males and $>=3.5 \mathrm{~g} / \mathrm{mol}$ in females based on a single urine test.

Participants in light clothes were weighed to the nearest $0.1 \mathrm{~kg}$. Height and WC were recorded to the nearest centimetre with the latter measured by the same technician at the level of the umbilicus. BP was the average of three measurements taken sitting after 10 min rest using a Dinamap model 800 automated blood pressure monitor (Critikon; Tampa FL, US). PA was self-reported and was categorized using the WHO criteria in which 'enough' means doing moderate to vigorous physical activity for more than $30 \mathrm{~min} /$ day for 5 days in the week before the survey. Daily number of cigarettes smoked and alcohol intake was also self-reported.

GGT, fasting total cholesterol, high density lipoprotein cholesterol (HDLC), triglycerides, and glucose were measured on fasting blood. GGT was measured using the kinetic photometric procedure with Cobas Integra 800 (Roche Diagnostics, www.roche-diagnostics.us/). Blood lipids and blood glucose were measured using photometric enzyme endpoint assay with Cobas Integra 700/400 (Roche Diagnostics, www.roche-diagnostics.us/).

Abdominal overweight was defined using WHO criteria as WC greater than $80 \mathrm{~cm}$ in females and $94 \mathrm{~cm}$ in males and obesity as greater than $88 \mathrm{~cm}$ in female and 102 in male. Baseline hypertension was ascertained either by detection of high BP at examination (measured BP $>=140$ / 90 ( $\mathrm{mmHg}$ ) or previous confirmed diagnosis or currently prescribed antihypertensive medication (by medical record review). Dyslipidaemia was defined as having triglycerides $>=2.0 \mathrm{mmol} / \mathrm{L}$ or HDLC $<1.0 \mathrm{mmol} / \mathrm{L}$ recommended by the National Heart Foundation. Diabetes was defined as either clinical diagnosis verified by the participants' medical records, a $2 \mathrm{~h}$ oral glucose tolerance test, or fasting blood glucose level $>7.0 \mathrm{mmol} / \mathrm{L}$.

\section{Analysis}

Prevalence of albuminuria at baseline and follow up was estimated using UACR measurements at two time points respectively, and its $95 \%$ confidence interval was computed using the binomial distribution. Prevalence was compared by baseline characteristics including age group ( $<35$ years vs $>=35$ years), sex, ethnicity, hypertension, fasting glucose or diabetes, blood lipids, GGT categories, smoking and drinking habits. The association between albuminuria at follow up and biomedical factors were explored using Generalised Linear Model with family of "binomial" and link of "logit". Prevalence rate ratio (OR) was adjusted for age, sex and ethnicity. The analysis was carried out using STATA 13 
(STATAcorp, College Station, Texas, USA) and significance level was set at two-sided $\mathrm{P}<0.05$.

\section{Results}

Among 1971 Indigenous participants aged 18 years and over (mean age 38.7 years) with available UACR measurements in the 19 communities, 64\% were overweight/obese. The prevalence of hypertension was $31 \%$ and diabetes was $17 \% .58 \%$ reported smoking and $70 \%$ self-reported as alcohol drinkers. 389 had albuminuria at baseline (19.7 \%, 95 \% CI: 18.0-21.6 \%). Those with albuminuria were more likely to be older, TSIs but not different by sex (Table 1). Overweight/obesity, and higher BP, glucose, and GGT were associated with baseline albuminuria independent of age, sex and ethnicity.

Figure 1 showed participants during the follow up period (1998-2007) by baseline albuminuria categories. In total, 566 people had the $2^{\text {nd }}$ UACR measurements, 182 had died, 427 had moved away from the communities, 21 were in prison, and 775 left with no reason recorded. The baseline characteristics by follow up status are summarized in the Additional file 1: Table S1. Briefly, compared to those who completed follow up, those not followed up were significantly younger, more likely to be Aboriginal

Table 1 Baseline characteristics of Indigenous adults in 19 communities from North Queensland 1998-2000 by albuminuria at baseline

\begin{tabular}{|c|c|c|c|}
\hline & Albuminuria $\mathrm{No}=1582$ & Albuminuria Yes $=389$ & Total N = 1971 \\
\hline & Mean or \% (95\% Cl) & Mean or \% $(95 \% \mathrm{Cl})$ & Mean or $\%(95 \% \mathrm{Cl})$ \\
\hline Age (Years) * & $36.8(36.1-37.5)$ & $46.5(45.0-48.0)$ & $38.7(38.1-39.4)$ \\
\hline Female \% & $50.6(48.2-53.1)$ & $48.8(43.9-53.8)$ & $50.3(48.1-52.5)$ \\
\hline Aboriginal \%* & $54.0(51.5-56.4)$ & $43.4(38.6-48.4)$ & $51.9(49.7-54.1)$ \\
\hline$W C(C M) *$ & $95.8(95.0-96.6)$ & $104.4(102.8-106.0)$ & $97.5(96.8-98.2)$ \\
\hline \multicolumn{4}{|c|}{ Abdominal overweight and obesity * \% } \\
\hline Overweight & $19.6(17.5-21.8)$ & $19.0(14.8-23.9)$ & $19.5(17.6-21.5)$ \\
\hline Obesity & $41.4(38.8-44.1)$ & $58.3(52.5-63.8)$ & $44.4(42.0-46.8)$ \\
\hline BMI $\left(\mathrm{kg} / \mathrm{m}^{2}\right)^{*}$ & $27.8(27.5-28.1)$ & $30.4(29.6-31.1)$ & $28.3(28.0-28.6)$ \\
\hline \multicolumn{4}{|l|}{$\mathrm{BMI} \%$ * } \\
\hline 25-29.9 & $27.0(24.9-29.3)$ & $25.2(21.1-29.9)$ & $26.7(24.8-28.7)$ \\
\hline$>=30$ & $34.4(32.1-36.8)$ & $50.9(45.9-55.9)$ & $37.7(35.5-39.8)$ \\
\hline $\mathrm{SBP}(\mathrm{mmHg}) *$ & $129.2(128.3-130.1)$ & $140.8(138.7-142.8)$ & $131.5(130.6-132.3)$ \\
\hline $\mathrm{DBP}(\mathrm{mmHg}) *$ & $71.0(70.3-71.7)$ & $77.5(76.2-78.8)$ & $72.3(71.7-72.9)$ \\
\hline Hypertension \% * & $26.4(24.3-28.6)$ & $49.9(44.9-54.8)$ & $31.0(29.0-33.1)$ \\
\hline Glucose $(\mathrm{mmol} / \mathrm{L}) *$ & $5.5(5.4-5.7)$ & $7.0(6.7-7.4)$ & $5.8(5.7-6.0)$ \\
\hline Diabetes \%* & $12.4(10.9-14.1)$ & $35.2(30.6-40.1)$ & $16.9(15.3-18.6)$ \\
\hline Cholesterol $(\mathrm{mmol} / \mathrm{L}){ }^{*}$ & $4.97(4.92-5.02)$ & $5.13(5.02-5.24)$ & $5.00(4.96-5.05)$ \\
\hline Triglycerides $(\mathrm{mmol} / \mathrm{L}) *$ & $1.87(1.79-1.94)$ & $2.12(1.95-2.29)$ & $1.92(1.85-1.99)$ \\
\hline $\mathrm{HDL}(\mathrm{mmol} / \mathrm{L})$ & $1.12(1.11-1.14)$ & $1.18(1.15-1.20)$ & $1.13(1.12-1.15)$ \\
\hline Dyslipidaemia \% & $46.8(44.3-49.3)$ & $49.5(44.4-54.5)$ & $47.3(45.1-49.5)$ \\
\hline GGT $(I U) *$ & $50.2(47.0-53.4)$ & $57.5(51.6-63.3)$ & $51.6(48.8-54.5)$ \\
\hline GGT $>50 \% *$ & $28.7(26.5-31.0)$ & $38.2(33.4-43.2)$ & $30.6(28.5-32.7)$ \\
\hline Smoker \% * & $60.4(58.0-62.8)$ & $49.2(44.3-54.2)$ & $58.2(56.0-60.4)$ \\
\hline \multicolumn{4}{|l|}{ Drinking status \% } \\
\hline Moderate & $23.4(21.4-25.6)$ & $20.4(16.6-24.7)$ & $22.8(21.0-24.7)$ \\
\hline Risky & $49.3(46.8-51.8)$ & $46.8(41.8-51.9)$ & $48.8(46.6-51.1)$ \\
\hline PA sufficient \% & $25.6(23.5-27.8)$ & $18.8(15.2-23.0)$ & $24.3(22.4-26.2)$ \\
\hline
\end{tabular}

${ }^{*} \mathrm{P}<0.05$ from ttest or chi square test or corresponding non-parametric tests

Abdominal overweight was defined using WHO criteria as WC greater than $80 \mathrm{~cm}$ in females and $94 \mathrm{~cm}$ in males and obesity as greater than $88 \mathrm{~cm}$ in female and 102 in male

Hypertension was ascertained either by detection of high BP at examination (measured BP > =140/90 (mmHg) or previous confirmed diagnosis or currently prescribed antihypertensive medication (by medical record review)

Diabetes was defined as either clinical diagnosis verified by the participants' medical records or a 2 hour oral glucose tolerance test, or fasting blood glucose level $>7.0 \mathrm{mmol} / \mathrm{L}$

Dyslipidaemia was defined as having triglycerides $>=2.0 \mathrm{mmol} / \mathrm{L}$ or $\mathrm{HDLC}<1.0 \mathrm{mmol} / \mathrm{L}$ recommended by National Heart Foundation 


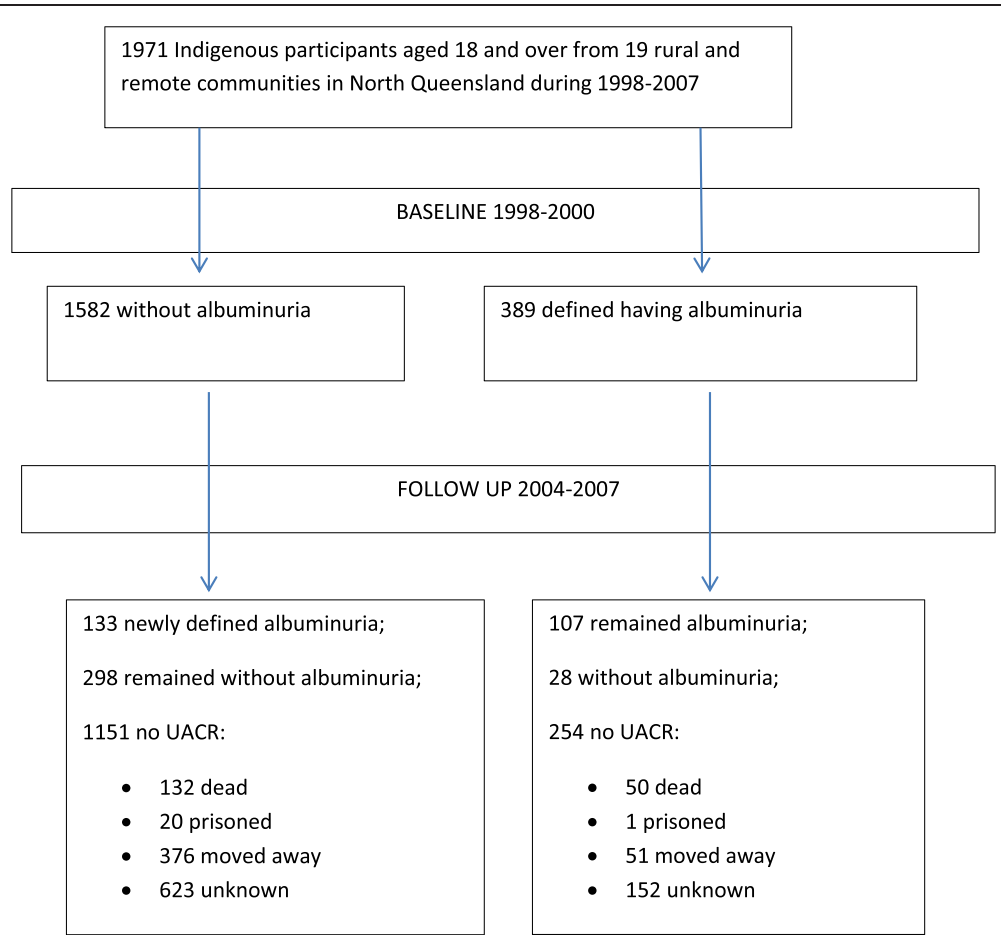

Fig. 1 UACR measurements and albuminuria among the participants at baseline and follow up surveys during 1998-2007

with significantly healthier biomedical measurements including BMI, systolic BP, and fasting blood glucose, but were also more likely to smoke tobacco, and/or drink alcohol. Among participants with baseline albuminuria, more had died or did not complete follow up, and fewer were imprisoned or moved away from the communities. People having the $2^{\text {nd }}$ UACR test were evenly distributed by baseline albuminuria categories.

Among the complete cohort, 201 were Aboriginal, 303 were TSI people and 62 were joint descendants. Aboriginal people had higher diastolic BP, triglycerides, and GGT, and a higher percentage of risky drinkers, but lower WC, BMI, and fasting glucose than the TSI participants. The demographic and biomedical characteristics of the complete cohort were similar to those among baseline population (Additional file 2: Table S2).

At the follow up, 133 new cases of albuminuria developed among those with normal UACR at baseline, while 107 baseline cases remained as albuminuria. Twentyeight went normal at the follow up (Fig. 1). The mean UACR of the 28 cases (12 of whom were females) was $1.2 \mathrm{~g} / \mathrm{mol}$ at follow up. To sum up, a total of 240 albuminuria cases were identified among 566 participants giving an overall follow up prevalence of albuminuria $42.4 \%$ (95 \% CI: 38.8-46.5 \%). The prevalence of albuminuria was higher than the baseline as shown in Fig. 2.

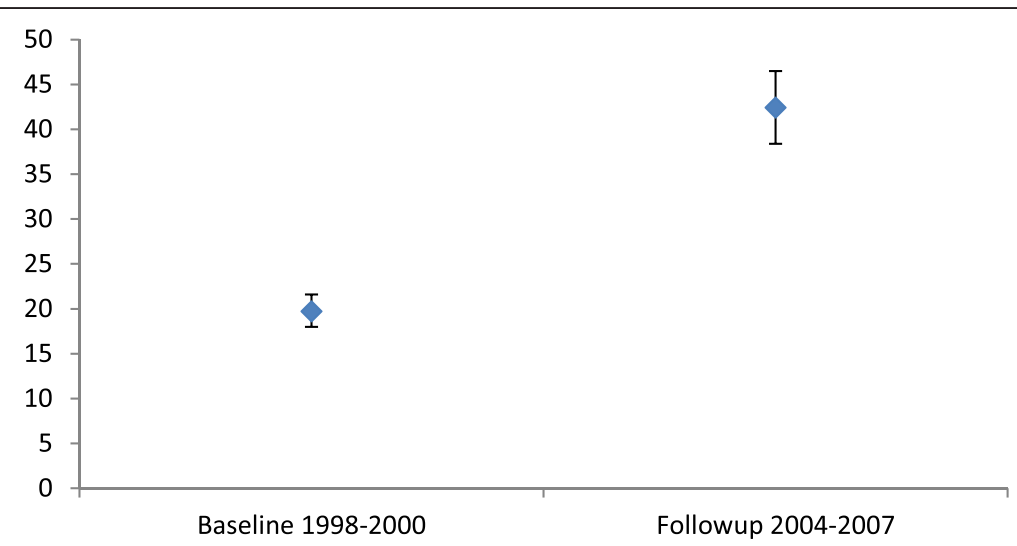

Fig. 2 Albuminuria prevalence among Indigenous adults in 19 rural and remote communities in North Queensland 1998-2007 
Table 2 shows the biomedical and behavioral characteristics of the complete cohort by follow up albuminuria. Participants with albuminuria at follow up were older or had higher BMI, BP, cholesterol, triglycerides, and GGT. Follow up albuminuria was not associated with drinking and PA and it was not significantly different by sex and ethnicity.

As shown in Table 3, in both Indigenous populations, diabetes was strongly associated with follow-up albuminuria (OR 2.7, 95 \% CI 1.8-4.2) after adjustment for age, sex, and ethnicity. Further analysis showed within the normal glucose range, that those with a baseline fasting glucose of more than $5.4 \mathrm{mmol} / \mathrm{L}$ had 2.5 times higher risk of albuminuria at follow up (OR: 2.5, $95 \%$ CI: $1.5-4.2)$ compared to less than $4.7 \mathrm{mmol} / \mathrm{L}$.

Baseline GGT > = 50 IU was associated with increased risk of albuminuria by 2.6 times (95 \% CI 1.7-3.9). A dose responsive effect of GGT with albuminuria was detected. Specifically, a GGT level of 25-47 IU associated with 2-fold prevalence of albuminuria (95 \% CI: $1.3-3.1$ ) and a level of $>=48$ by 3.7 times (95\% CI: 2.2-6.2) compared to a level of $<25$ IU ( $p$ for trend $<0.001$ ). Abdominal overweight and obesity was associated with albuminuria at follow up by 2.1 (95\% CI: 1.1-3.9) and 5.4 (95 \% CI: 2.2-13.5) respectively.

Table 2 Baseline characteristics of Indigenous adults in 19 communities from North Queensland by albuminuria at follow up

\begin{tabular}{|c|c|c|}
\hline & Albuminuria $\mathrm{No}=326$ & Albuminuria Yes $=240$ \\
\hline & Mean or \% $(95 \% \mathrm{Cl})$ & Mean or \% $(95 \% \mathrm{Cl})$ \\
\hline Age (Years) * & $38.4(37.0-39.8)$ & $44.7(43.0-46.3)$ \\
\hline Female \% & $52.1(46.7-57.5)$ & $44.6(38.4-51.0)$ \\
\hline Aboriginal \% & $32.8(27.9-38.1)$ & $39.2(33.2-45.5)$ \\
\hline WC $(C M) *$ & $97.9(96.1-99.8)$ & $105.8(103.8-107.8)$ \\
\hline \multicolumn{3}{|c|}{ Abdominal overweight and obesity * \% } \\
\hline Overweight & $18.5(14.4-23.6)$ & $19.6(14.3-26.4)$ \\
\hline Obesity & $46.2(40.3-52.1)$ & $58.3(50.7-65.6)$ \\
\hline BMI $\left(\mathrm{kg} / \mathrm{m}^{2}\right)^{*}$ & $28.7(27.9-29.6)$ & $31.0(30.1-31.8)$ \\
\hline \multicolumn{3}{|l|}{$\mathrm{BMI} \%$ * } \\
\hline 25-29.9 & $26.6(22.1-31.7)$ & $22.2(17.3-27.9)$ \\
\hline$>=30$ & $40.2(35.0-45.7)$ & $55.2(48.8-61.4)$ \\
\hline $\mathrm{SBP}(\mathrm{mmHg}) *$ & $130.0(128.0-131.9)$ & $137.3(135.0-139.6)$ \\
\hline $\mathrm{DBP}(\mathrm{mmHg}) *$ & $71.5(70.1-73.0)$ & $75.3(73.6-77.1)$ \\
\hline Hypertension \% * & $31.4(26.6-36.7)$ & $44.2(38.0-50.5)$ \\
\hline Glucose $(\mathrm{mmol} / \mathrm{L}) *$ & $5.5(5.3-5.8)$ & $6.8(6.3-7.2)$ \\
\hline Diabetes \%* & $15.0(11.5-19.4)$ & $35.4(29.6-41.7)$ \\
\hline Cholesterol $(\mathrm{mmol} / \mathrm{L}){ }^{*}$ & $4.9(4.8-5.0)$ & $5.3(5.2-5.5)$ \\
\hline Triglycerides $(\mathrm{mmol} / \mathrm{L}) *$ & $1.7(1.5-1.8)$ & $2.4(2.2-2.7)$ \\
\hline $\mathrm{HDL}(\mathrm{mmol} / \mathrm{L})^{*}$ & $1.12(1.09-1.15)$ & $1.08(1.04-1.12)$ \\
\hline Dyslipidaemia \% * & $42.3(37.0-47.8)$ & $60.0(53.5-66.2)$ \\
\hline GGT (IU) * & $40.5(36.0-45.0)$ & $64.2(53.2-75.3)$ \\
\hline GGT $>50 \% *$ & $19.2(15.2-23.9)$ & $39.6(33.4-46.1)$ \\
\hline Smoker \% & $49.2(43.8-54.7)$ & $55.5(49.1-61.7)$ \\
\hline \multicolumn{3}{|l|}{ Drinking status \% } \\
\hline Moderate & $25.6(21.1-30.8)$ & $20.6(15.9-26.2)$ \\
\hline Risky & $41.5(36.1-47.0)$ & $44.1(37.9-50.5)$ \\
\hline PA sufficient \% & $28.2(23.6-33.4)$ & $26.7(21.4-32.6)$ \\
\hline
\end{tabular}

${ }^{*} \mathrm{P}<0.05$ from ttest or chi square test or corresponding non-parametric tests

Abdominal overweight was defined using WHO criteria as WC greater than $80 \mathrm{~cm}$ in females and $94 \mathrm{~cm}$ in males and obesity as greater than $88 \mathrm{~cm}$ in female and 102 in male

Hypertension was ascertained either by detection of high BP at examination (measured BP $>=140 / 90$ (mmHg) or previous confirmed diagnosis or currently prescribed antihypertensive medication (by medical record review)

Diabetes was defined as either clinical diagnosis verified by the participants' medical records or a 2 hour oral glucose tolerance test, or fasting blood glucose level $>7.0 \mathrm{mmol} / \mathrm{L}$

Dyslipidaemia was defined as having triglycerides $>=2.0 \mathrm{mmol} / \mathrm{L}$ or $\mathrm{HDLC}<1.0 \mathrm{mmol} / \mathrm{L}$ recommended by National Heart Foundation 
Table 3 Biomedical factors associated with follow-up albuminuria among Indigenous adults in 19 communities from North Queensland (OR and 95\% Cl)

\begin{tabular}{|c|c|c|c|c|c|c|}
\hline & \multicolumn{2}{|l|}{ Aboriginal } & \multicolumn{2}{|l|}{ TSI } & \multicolumn{2}{|l|}{ Overall } \\
\hline & Crude & Adjusted $^{a}$ & Crude & Adjusted $^{a}$ & Crude & Adjusted $^{b}$ \\
\hline \multicolumn{2}{|c|}{ Abdominal overweight/obesity } & "No" as referer & & & & \\
\hline Overweight & $1.9(0.8-4.3)$ & $2.2(0.9-5.6)$ & $3.4(1.2-9.9)$ & $2.8(0.9-8.4)$ & $1.7(1.0-3.0)$ & $2.1(1.1-3.9)$ \\
\hline Obesity & $2.3(1.2-4.4)$ & $5.7(1.8-18.6)$ & $4.2(1.7-10.7)$ & $8.8(1.6-49.5)$ & $2.0(1.3-3.2)$ & $5.4(2.2-13.5)$ \\
\hline $\mathrm{GGT}>=50 \mathrm{IU}$ & \multicolumn{4}{|c|}{ "<50" as reference } & & \\
\hline Yes & $2.0(1.1-3.6)$ & $2.1(1.1-4.1)$ & $2.8(1.6-5.1)$ & $2.6(1.4-5.0)$ & $2.8(1.9-4.1)$ & $2.6(1.7-3.9)$ \\
\hline GGT tertiles & \multicolumn{4}{|c|}{ " $<25 \mathrm{IU}$ " as reference } & & \\
\hline $25-47$ & $1.5(0.7-3.4)$ & $1.2(0.5-2.9)$ & $2.5(1.4-4.3)$ & $2.4(1.3-4.3)$ & $2.2(1.4-3.3)$ & $2.0(1.3-3.1)$ \\
\hline$>=48$ & $2.5(1.2-5.3)$ & $2.3(1.0-5.4)$ & $4.2(2.2-8.2)$ & $4.2(2.0-8.7)$ & $4.0(2.5-6.2)$ & $3.7(2.2-6.2)$ \\
\hline Hypertension & \multicolumn{4}{|c|}{ " $<140 / 90 \mathrm{mmHg}$ " as reference } & & \\
\hline Yes & $2.2(1.2-3.9)$ & $1.6(0.9-3.1)$ & $1.4(0.9-2.2)$ & $1.0(0.6-1.7)$ & $1.7(1.2-2.4)$ & $1.2(0.8-1.8)$ \\
\hline Diabetes & \multicolumn{4}{|c|}{ "No" as reference } & & \\
\hline Yes & $6.1(2.5-14.7)$ & $5.8(2.4-14.6)$ & $2.5(1.5-4.1)$ & $2.0(1.2-3.5)$ & $3.1(2.1-4.6)$ & $2.7(1.8-4.2)$ \\
\hline Glucose tertiles & \multicolumn{4}{|c|}{ "<4.7 mmol//L" as reference } & & \\
\hline $4.7-5.3$ & $1.8(0.9-3.8)$ & $1.7(0.8-3.6)$ & $1.5(0.8-3.0)$ & $1.2(0.6-2.4)$ & $1.4(0.9-2.2)$ & $1.4(0.9-2.3)$ \\
\hline$>=5.4$ & $4.2(2.0-9.1)$ & $3.8(1.7-8.4)$ & $2.7(1.4-5.2)$ & $1.9(0.9-3.9)$ & $2.4(1.5-3.8)$ & $2.5(1.5-4.2)$ \\
\hline Current smoker & \multicolumn{4}{|c|}{ "No" as reference } & & \\
\hline Yes & $1.0(0.6-1.8)$ & $1.0(0.6-1.9)$ & $1.7(1.1-2.7)$ & $2.0(1.2-3.2)$ & $1.3(0.9-1.8)$ & $1.4(1.0-2.0)$ \\
\hline
\end{tabular}

adjusted for age and sex in each ethnic group, further adjusted for ethnicity in overall population

Abdominal overweight was defined using WHO criteria as WC greater than $80 \mathrm{~cm}$ in females and $94 \mathrm{~cm}$ in males and obesity as greater than $88 \mathrm{~cm}$ in female and 102 in male

Hypertension was ascertained either by detection of high BP at examination (measured BP $>=140 / 90$ (mmHg) or previous confirmed diagnosis or currently prescribed antihypertensive medication (by medical record review)

Diabetes was defined as either clinical diagnosis verified by the participants' medical records or a 2 hour oral glucose tolerance test, or fasting blood glucose level $>7.0 \mathrm{mmol} / \mathrm{L}$

Dyslipidaemia was defined as having triglycerides $>=2.0 \mathrm{mmol} / \mathrm{L}$ or $\mathrm{HDLC}<1.0 \mathrm{mmol} / \mathrm{L}$ recommended by National Heart Foundation

Aboriginal people having diabetes were 3 times more likely than TSI diabetes patients to have albuminuria at follow up. TSI smokers were twice as likely to have albuminuria compared to non-smokers, but this effect was not demonstrated among Aboriginal participants.

\section{Discussion}

This study found a high baseline prevalence of albuminuria (20\%) among adults from rural and remote communities in north Queensland, especially among those aged over 25 years. And baseline albuminuria was associated with features of the metabolic syndrome (BMI, BP, dyslipidaemia and glucose) and higher GGT levels. This is consistent with the prevalence and associated factors reported in other Aboriginal communities in NT, SA, WA, and QLD [14-16]. The prevalence is 3 times higher than the prevalence found in the national nonIndigenous sample (AusDiab) [11].

Indigenous people in rural and remote communities had more than double the risk of follow up albuminuria at an early age compared contemporarily to the non-Indigenous Australians from the AusDiab study, similar to findings from an Aboriginal population in the NT [22]. The prevalence at follow up was more than twice of the baseline during a median 7 years of follow up.

We found consistently that increased fasting glucose or diabetes was associated with albuminuria at both occasions. The baseline prevalence of diabetes/impaired glucose tolerance in Indigenous population was between 3 and 5 times higher than the comparable rates for non-Indigenous people in all age groups from 25 years and over [23]. We have reported that the diabetes incidence in this cohort was 4 times that of nonIndigenous people and appeared to be increasing over the estimates from a decade previously [17]. As albuminuria is a key early marker of future CKD and ESRD, Indigenous Australians are at particularly high risk, and evidence for effective primary care level management is strong. Therefore early screening for albuminuria is important in this population [24]. Our finding that abdominal overweight and obesity predicted albuminuria independently of diabetes is consistent with other cohort studies among south Asians and Chinese [25, 26]. Apart from secondary prevention of ESRD with drugs, surgical intervention to reduce obesity has proved 
highly effective in reducing albuminuria incidence among obese Swedish subjects [27]. The underlying mechanisms may include renin-angiotensin-aldosterone system activation, leptin, adiponectin, fetuin- $\mathrm{A}$, and adipose tissue inflammation, as factors that contribute to glomerulonephritis, focal and segmental glomerulosclerosis, and IgA nephropathy [28].

Tobacco smoking is highly prevalent among Indigenous Australians and was associated with albuminuria at both baseline and follow up. This finding is similar to other studies in Europeans, Americans and Asians [29-31]. Smoking predicted albuminuria or proteinuria in the Framingham Offspring Cohort [32] and Japanese adults [33] but not among the European PREVEND cohort [34].

GGT, as a marker of liver disease and alcohol intake and as a biomarker of oxidative stress [35], was associated with albuminuria in a dose-responsive manner in the two Indigenous populations after adjustment for demographics, overweight and obesity, diabetes, hypertension, and smoking and drinking habits. The results were similar to the systematic review on the association between GGT and albuminuria or CKD in both cross sectional and follow up studies among Americans and Koreans [36]. We have reported that GGT predicts hypertension incidence [37] and is highly correlated with overweight and obesity. Metabolic syndrome and alcohol drinking magnifies the association between GGT and metabolic components among this population [38, 39]. Further exploration of its association with cardiovascular conditions and diabetes is needed to understand the additional independent impact of GGT on albuminuria found in this population for better risk evaluation or stratification in Indigenous population.

Strengths of this study include a representative community-based sample of both Aboriginal and TSI populations and objective clinical measurements. TSIs are the second group of Indigenous Australians who inhabit the islands of Torres Strait as a part of Queensland. They have a heavier phenotype and a healthier lifestyle compared to Aborigines. The data collected in this study enabled us to compare albuminuria and its associated biomedical factors between the two ethnic groups. Although the risk profiles in the two populations are different, the albuminuria prevalence was not statistically different, partly due to the higher risk for Aboriginal people given the same level of increased glucose or diabetes, and/ or less risk for Aboriginal smokers compared to TSIs, or disproportionally increased loss of Aboriginal participants, including those with baseline albuminuria.

Limitations should be noted. Firstly, the definition of albuminuria was based on a single UACR measurement due to the study design of screening a large general population from communities with limited resources, which could misclassify cases. The follow up data showed a small number of baseline micro albuminuria cases were normal at follow up. Secondly, the follow up information was not completed to sufficiently facilitate the estimation of the incidence rate, especially for those who moved from the communities. Thirdly, a large number of relatively healthier Aboriginal participants lost contact at the follow up which could result in overestimate of the prevalence at follow up. Lastly, we could not detail medical and family history, and some potential confounders to explore albuminuria and its predictors. For example, studies among Aboriginal Australians in remote communities show that earlier infection is strongly associated with kidney dysfunction in later life $[40,41]$. In spite of these, this study documented the prevalence from a representative population for both Aboriginal and TSI groups in rural and remote communities in North Queensland at baseline and the follow up albuminuria in a selected group of high risk participants including important biomedical factors.

\section{Conclusions}

The high prevalence of albuminuria in the Indigenous Australian population was associated with excessive risk of glycaemia, diabetes, obesity, increased GGT, or smoking. Early screening and management of these factors are essential to stem the tide of ESRD and CVD in this population.

\section{Additional files}

Additional file 1: Table S1. Characteristics of participants by follow up status. (DOCX $20 \mathrm{~kb}$ )

Additional file 2: Table S2. Characteristics of participants at follow up by ethnicity. (DOCX $21 \mathrm{~kb}$ )

\section{Abbreviations}

CKD: Chronic kidney disease; AusDiab study: The Australian Diabetes, Obesity and lifestyle Study; UACR: Urine albumin creatinine ratio; TSI: Torres strait islanders; NT: Northern Territory; SA: South Australia; WA: Western Australia; QLD: Queensland; ESKD: End-stage kidney disease; BP: Blood pressure; PA: Physical activity; GGT: Gamma-glutamyl transferase; HDLC: High density lipoprotein cholesterol; WC: Waist circumference; OR: hazard ratios.

\section{Competing interests}

The authors declare that they have no competing interests.

\section{Authors' contributions}

ML conducted the data analysis, interpreted the results and composed the manuscript. RM designed the project and edited the manuscript. Both authors read and approved the final manuscript.

\section{Acknowledgements}

Our thanks to the health staff in the participating communities and to the Aboriginal and Torres Strait Islander Health Council for their support for the project. The study was funded by National Health and Medical Research Council (Grant number 279402) and the Department of Health and Ageing, Australia. 


\section{Author details}

${ }^{1}$ Centre for Population Health Research, Sansom Institute for Health Research, University of South Australia, IPC CWE-48, GPO Box 2471, Adelaide, SA 5001, Australia. ${ }^{2}$ Faculty of Medicine, Health \& Molecular Sciences, James Cook University, Cairns, QLD 4870, Australia.

Received: 15 September 2015 Accepted: 30 November 2015 Published online: 10 December 2015

\section{References}

1. Zhang Q, Rothenbacher D. Prevalence of chronic kidney disease in population-based studies: systematic review. BMC Public Health. 2008; doi: 10.1186/1471-2458-8-117

2. Nahas AMEL, Bello A. Chronic kidney diseases: the global challenge. Lancet. 2005;365:331-40

3. James MT, Hemmelgarn BR, Tonelli M. Early recognition and prevention of chronic kidney disease. Lancet. 2010;375:1296-309.

4. Johnson DW, Jones GRD, Mathew TH, Ludlow MJ, Chadban SJ, Usherwood T, et al. Chronic kidney disease and the measurement of albuminuria or proteinuria: a position statement. MJA. 2012;194:1-6.

5. de Jong PE, Curhan GC. Screening, monitoring, and treatment of albuminuria: Public health perspectives. J Am Soc Nephrol. 2006;17:2120-26.

6. Boulware LE, Jaar BG, Tarver-Carr ME, Brancati FL, Powe NR. Screening for proteinuria in US adults: a cost-effective analysis. JAMA. 2003;290:3101-14.

7. Hoerger TJ, Wittenborn JS, Segel JE, Burrows NR, Imai K, Eggers P, et al. A health policy model of CKD: 2 . The cost-effectiveness of microalbuminuria screening. Am J Kidney Dis. 2010;55:463-73.

8. Chronic Kidney Disease Prognosis Consortium. Association of estimated glomerular filtration rate and albuminuria with all-cause and cardiovascular mortality: a collaborative meta-analysis of general population cohorts. Lancet. 2010;375:2073-81.

9. Ninomiya T, Perkovic V, de Galan BE, Zoungas S, Pillai A, Jardine M, et al. Albuminuria and kidney function independently predict cardiovascular and renal outcome in diabetes. J Am Soc Nephrol. 2009;20:1813-21.

10. Hoy WE, Wang Z, VanBuyder P, Baker PR, McDonald SM, Mathews JD. The natural history of renal disease in Australian Aborigines. Part 2. Albuminuria predicts natural death and renal failure. Kidney Int. 2001;60:249-56.

11. Atkins RC, Polkinghorne KR, Briganti EM, Shaw JE, Zimmet PZ, Chadban SJ. Prevalence of albuminuria in Australia: The AusDiab Kidney Study. Kidney Int. 2004;66:Suppl 22-4.

12. Barr ELM, Magliano DJ, Zimmet PZ, Polkinghorne KR, Atkins RC, Dunstan DW, et al. The Australian diabetes, obesity and lifestyle study- AusDiab 2005. Melbourne, Australia: International Diabetes Institute; 2006.

13. Australian Institute of Health and Welfare. Chronic kidney disease in Aboriginal and Torres Strait Islander people. 2011. Cat. No. PHE151. Canberra.

14. Hoy WE, Mathews JD, Mccredie DA, Pugsley DJ, Hayhurst BG, Rees M, et al. The multidimensional nature of renal disease: Rates and associations of albuminuria in an Australian Aboriginal community. Kidney Int. 1998:54:1296-304.

15. Rowley KG, Iser DM, Best JD, O'Dea K, Leonard D, McDermott R. Albuminuria in Australian Aboriginal people: prevalence and associations with components of the metabolic syndrome. Diabetologia. 2000;43:1397-403.

16. Shephard MDS, Allen GG, Barratt L, Paizis K, Brown M, Barbara JAJ. et al. Albuminuria in a remote South Australian Aboriginal community: results of a community-based screening program for renal disease. Rural and Remote Health 3 (online), 2003. http://rrh.org.au. Accessed 15 May 2015.

17. McDermott R, Li M, Campbell S. Incidence of type 2 diabetes in two Indigenous Australian populations: a 6-year follow-up study. MJA. 2010;192:562-5.

18. Li M, McCulloch B, McDermott R. Metabolic Syndrome and incident coronary heart disease in Australian Indigenous populations. Obesity. 2012; doi:10.1038/oby.2011.156.

19. McDermott R, McCulloch B, Li M. Glycaemia and albuminuria as predictors of coronary heart disease in Aboriginal and Torres Strait Islander adults: a north Queensland cohort. MJA. 2011;194:514-8.

20. Li M, McDermott R. Obesity, albuminuria, and gamma-glutamyl transferase predict incidence of hypertension in Indigenous Australians in rural and remote communities in northern Australia. J Hypertens. 2015;33:704-10.
21. Miller G, McDermott R, McCulloch B, Leonard D, Arabena K, Muller R. The Well Person's Health Check: a population screening program in indigenous communities in north Queensland. Aust Health Rev. 2002;25:136-47.

22. Hoy WE, Kondalsamy-chennakesavan S, Wang Z, Briganti E, Shaw J, Polkinghorne K, et al. Quantifying the excess risk for proteinuria, hypertension and diabetes in Australian Aborigines: comparison of profiles in three remote communities in the Northern Territory with those in the AusDiab study. Aust N Z J Public Health. 2007;31:177-83.

23. Australian Bureau of Statistics. Australian Aboriginal and Torres Strait Islander Health Survey: First Results, Australia, 2012-13.2013. cat no.4727.0. 55.001. Canberra: Australian Bureau of Statistics; 2014. www.abs.gov.au/ ausstats/abs@.nsf/mf/4727.0.55.001. Accessed 01 March 2014.

24. Tuttle KR, Bakris GL, Bilous RW, Chiang JL, de Boer IH, Goldstein-Fuchs J, et al. Diabetic kidney disease: a report from an ADA consensus conference. Diabetes Care. 2014;37:2864-83.

25. Shaw C, Berger SP, Mallat M. Central obesity is an independent risk factor for albuminuria in nondiabetic South Asian subjects. Diabetes Care. 2007;30:1840-44

26. Lin WY, Pi-Sunyer FX, Liu CS, Li Cl, Davidson LE, Li TC. et al. Central obesity and albuminuria: both cross-sectional and longitudinal studies in Chinese. PLOS ONE. 2012; doi:10.1371/journal.pone.0047960.

27. Carlsson LMS, Jacobson P, Burza MA, Burza MA, Maglio C, Sjöholm K, et al. The incidence of albuminuria after bariatric surgery and usual care in Swedish obese subjects (SOS): a prospective controlled intervention trial. Int J Obes (Lond). 2015;39:169-75.

28. Kalaitzidis RG, Siamopoulos KC. The role of obesity in kidney disease: recent findings and potential mechanisms. Int Urol Nephrol. 2011;43:771-84.

29. Pinto-Sietsma SJ, Mulder J, Janssen WM, Hillege HL, de Zeeuw D, de Jong PE. Smoking is related to albuminuria and abnormal renal function in nondiabetic persons. Ann Intern Med. 2000;133:585-91.

30. Ishizaka N, Ishizaka Y, Toda E, Shimomura H, Koike K, Seki G, et al. Association between cigarette smoking and chronic kidney disease in Japanese men. Hypertens Res. 2008;31:485-92.

31. Hogan SL, Vupputuri S, Guo X, Cai J, Colindres RE, Heiss G, et al. Association of cigarette smoking with albuminuria in the United States: The Third National Health and Nutrition Examination Survey. Ren Fail. 2007;29:133-42.

32. O'Seaghdha CM, Hwang SJ, Upadhyay A, Meigs JB, Fox CS. Predictors of incident albuminuria in the Framingham Offspring Cohort. Am J Kidney Dis. 2010;56:852-60.

33. Yamagata K, Ishida K, Sairenchi T, Takahashi H, Ohba S, Shiigai T, et al. Risk factors for chronic kidney disease in a community-based population: a 10-year follow-up study. Kidney Int. 2007;71:159-66.

34. Brantsma AH, Atthobari J, Bakker SJ, de Zeeuw D, de Jong PE, Gansevoort RT. What predicts progression and regression of urinary albumin excretion in the nondiabetic population? J Am Soc Nephrol. 2007;18:637-45.

35. Lee DH, Blomhoff R, Jacobs Jr DR. Is serum Gamma glutamyltransferase a marker of oxidative stress? Free Radic Res. 2004;38:535-9.

36. Fassett RG, Venuthurupalli SK, Gobe GC, Coombes JS, Cooper MA, Hoy WE. Biomarkers in chronic kidney disease: a review. Kidney Int. 2011;80:806-21.

37. Li M, McDermott R. Obesity, albuminuria, and gamma-glutamyl transferase predict incidence of hypertension in Indigenous Australians in rural and remote communities in northern Australia. J Hypertens. 2015;33:704-10.

38. Li M, Campbell S, McDermott R. Gamma-Glutamyltransferase, obesity, physical activity, and the metabolic syndrome in indigenous Australian adults. Obesity. 2009;17:809-13.

39. Haren MT, Li M, Petkov J, McDermott RA. Alcohol, metabolic risk and elevated serum gamma-glutamyl transferase (GGT) in Indigenous Australians. BMC Public Health. 2010;10:454. doi:10.1186/1471-2458-10-454.

40. Hoy WE, White AV, Dowling A, Sharma SK, Bloomfield H, Tipiloura BT, et al. Post-streptococcal glomerulonephritis is a strong risk factor for chronic kidney disease in later life. Kidney Int. 2012;81:1026-32.

41. Hoy WE, White AV, Tipiloura B, Singh GR, Sharma S, Bloomfield $H$, et al. The influence of birth-weight, past post-streptococcal glomerulonephritis and current body mass index on levels of albuminuria in young adults: the multideterminant model of renal disease in a remote Australian Aboriginal population with high rates of renal disease and renal failure. Nephrol Dial Transplant. 2014;0:1-7. doi:10.1093/ndt/gfu241. 